\title{
Illness as an opportunity to awaken consciousness
}

\author{
Volume 7 Issue 3 - 2017 \\ Paul Epstein ND \\ Naturopathic Physician and Healing Coach, Mind-Body \\ Integrative Medicine, USA
}

\section{Opinion}

When we are sick and in pain we try to get well quickly. This is the natural response. We seek treatments to 'fix' or get rid of our pain and symptoms so we can get back to our normal lives. When the treatment doesn't make the symptoms go away, and we begin to suffer physically and emotionally, our search for answers intensifies.

As a naturopathic physician, practicing holistic medicine and natural healing, people come to me hoping I can help them out of their pain and suffering. Some have been told, "Nothing can be done". They will tell me "I don't know if you can help me" you are my last resort. "I'm sick and tired of being sick and tired, I've got to do something-anything." They often feel frustrated, angry, afraid, hopeless, desperate, impatient, distrustful and resistant. They're worn out not just from the disease, but also from the battle to get well.

At this point, illness provides the opportunity to embark on a journey of self-discovery and healing. Instead of supporting continued efforts to get rid of their disease, a new approach and fresh perspective is needed and possible-an approach that asks new questions and allows a shift in attitudes and a new relationship with their disease.

\section{Where's the healing?}

"Our disease may tell the story of ourselves, not just our cells. By taking the risk of listening, we may be led to the emotions, both positive and negative that lie at the core of our authentic being. "Mark Barasch author The Healing Path.

I don't encourage people in perpet-uating an attitude and a relationship with their symptoms that does not work and has not worked. Looking at symptoms as separate from the rest of our lives splits the body from the mind and spirit. When we try to get rid of our pain and symptoms, we deepen the split. Even if we do remove the symptoms, the underlying systemic cause and real message the disease is telling us, may not have been addressed therefore only temporary relief is attained, and deeper healing isn't happening.

\section{Seeing with new eyes}

"The journey of discovery lies not in seeking new landscapes - it is in seeing with new eyes."

"You cannot solve a problem from the same perspective that created it"

Despair can turn into hope, impatience can turn into patience, fear can turn into courage and resistance can turn into acceptance. In the willingness to look and see with new eyes, healing becomes possible. We begin to see and hear the messages of illness and symptoms. Our bodies are telling us something. Learning to understand these messages can be the key that unlocks the door to recovery. Working with mind-body medicine we explore.... Where is the healing? The crisis of illness thus becomes the vehicle for transformation and healing from within.

\author{
Correspondence: Naturopathic Physician and Healing Coach, \\ Mind-Body Integrative Medicine, USA, 42 Richmondville Ave, \\ Westport, Ct. 06880, USA, Tel 203-226-3923, \\ Email epsteinmb@aol.com
}

Received: May 22, 2017 | Published: June 02, 2017

\section{Creating a healing environment}

A shift in ones perspective allows a person to create a context for healing as much as any conventional therapy or treatment. This emotional psychological and spiritual context- the 'healing environment' may be more important to the healing process than any particular medicine or therapy. For there is no one therapy or treatment protocol or sure-fire method for any particular chronic disease.

Ever patient has a unique history, the background for their disease, and healing is an individual, personal and solitary journey. A holistic approach seeks to integrate and synergize the more clinical aspects of a treatment plan with the mind, emotions attitudes and beliefs. As people work to create this' healing environment' in their lives, they need guidance and support.

\section{Shifting roles for doctor and patient}

Offering guidance and support during the journey of healing means the roles of the doctor and patient must shift. In addition to providing appropriate therapies, the doctor must also become a guide, teacher, coach and an advocate in helping patients learn from their dis-ease and illness.

The patient in turn, takes responsibility for their illness and works in creating the proper environment for their healing. By opening to the symptoms, listening to the illnesses message, and believing healing and change are possible, the healing process is stimulated. Together the doctor and patient form a healing relationship, an important component of the healing environment.

"Healing is what happens at the level of the whole person, and it requires collaboration with the innate movement towards wholeness which is constant and present in everyone. Healing is not the outcome of an interaction between an expert and a problem; it requires a relationship between two whole human beings who bring to a situation of suffering the full power of their combined humanity and all of its potential. When this happens many things that cannot be cured can still heal.

"The hope of healing is always present. Even faced by an incurable disease, a person may still grow in such a way that, over time, the 
wound of their illness becomes a smaller and smaller part of the sum of their lives, because wholeness exists even in the presence of disease."

\section{Healing our whole lives}

"Perhaps all the dragons in our lives are princesses only waiting to see us act once, with beauty and courage. Perhaps everything that frightens us is, in its deepest essence, something that feels helpless and needs our love. (Rilke)

Am I willing to listen with the ears of my heart to the other voices of myself speaking?

We carry the effects of growing up in dysfunctional families, resulting from physical and /or emotional abuse, abandonment, neglect and or enmesh-ment with us in our bodies and our lives. Often childhood wounds we carry are held and expressing themselves in illness and disease. We may only start to recover when we face our truth and feel the unexpressed emotions and feelings that have been buried deep inside. We have to re-experience and release these long held emotions and support our healing, mind, heart, body and soul.

"If there is a single definition of healing, it is to touch with mercy and awareness those pains, mental, emotional and physical, from which we have withdrawn in judgment and dismay."

Mind/body medicine techniques and therapies help us make the healing connections between our biography and our biology, between our past, our lives and our bodies, minds and spirits. Bill Moyer's PBS Series 'Healing the mind' illustrates the increased scientific and public interest in this approach to healing. And people increasingly understand that these therapies and techniques work. You can see this by the many people in the 12 step recovery movement (Alcoholics, emotions, Narcotics anonymous etc.,) and the success of John Bradshaw's work, to give just two example.

Many people are involved in their personal journey to finding their true self and healing the wounded child inside.

They are discovering and experiencing that; releasing anger can help heart disease, Healing fears and anxieties can help asthma,
Healing the pain of resentment can help a person with cancer, Freeing the guilt and shame of childhood abuse can help with irritable bowel syndrome, Dealing with stress in a marriage can help heal arthritis.

The importance of the mind/body connection is sometimes dramatically obvious. For example, a woman came to me with rheumatoid arthritis in her hands which had gotten progressively worse over a three year period. Her increasing doses of steroidal antiinflammatory drugs did not resolve her pain and she faced the nearterm prospect of surgery if the medication was ineffective.

After guiding her in diet changes and prescribing supplements (vitamins, minerals herbs and homeopathics), we then explored her stress and deeper emotional issues. She was still clinging to the grief and fear from the sudden death of her husband to whom she was married for 33years. Her arthritis symptoms began not coincidentally, soon after his death. She hadn't been able to fully grieve and was also very fearful and guilt ridden of establishing new relationships and dating still three years later. She needed to let go to move on with her life, mind, body, heart and healing. By supporting her in releasing her suppressed feelings and emotions, and in conjunction with natural therapies and a referral to a family therapist, she was able over time to avoid surgery and gradually reduce her dependency on toxic drugs. Today her hands are healed and she is off medication.

By facing and embracing the truth of our lives which may be manifesting in our dis-ease, pain, grief, fear, and toxic shame, we can heal not just our symptoms and dis-ease, but our whole being.

\section{Acknowledgments}

None.

\section{Conflicts of interest}

Author declares there are no conflicts of interest.

\section{Funding}

None. 